\title{
DECAY RESISTANCE, HARDNESS, WATER ABSORPTION, AND THICKNESS SWELLING OF A BAGASSE FIBER/PLASTIC COMPOSITE
}

\author{
Seyyed Khalil Hosseinihashemi, ${ }^{a, *}$ Mahdi Modirzare, ${ }^{\mathrm{a}}$ Vahidreza Safdari, ${ }^{\mathrm{a}}$ and \\ Behzad Kord ${ }^{\text {b }}$
}

\begin{abstract}
The decay resistance, hardness, water absorption, and thickness swelling of a bagasse fiber/polypropylene composite were evaluated. Brown- (Coniophora puteana) and white-rot (Trametes versicolor) fungal treatments were applied for 8,12 , and 16 weeks according to BS 838:1961 with the kolle-flask method. The brown- and white-rotted, and control composite samples were immersed in distilled water at $2 \mathrm{~h}$ and $24 \mathrm{~h}$ to measure the water absorption and thickness swelling of samples according to the ASTM D 570-98 requirements. Results indicated that the both lowest (3.2\%) and the highest (7.2\%) weight loss were observed in the white-rotted composite samples for 8 and 16 weeks fungal exposure times, respectively. The highest hardness (77.6 Shore D) was noted in the control composite samples, and the lowest hardness (65.5 Shore D) was recorded in the white-rotted composite samples. The highest water absorption (10.5\%) was observed in the brown-rotted composite samples for 8 weeks fungal exposure time and after $24 \mathrm{~h}$ immersion in distilled water, and the lowest $(3.8 \%)$ was noted in the control composite samples after $2 \mathrm{~h}$ immersion in distilled water. The highest thickness swelling (6.3\%) was observed in the control composite samples after $24 \mathrm{~h}$ immersion in distilled water, and the lowest thickness swelling (1.9\%) was found in the white-rotted composite samples for 16 weeks fungal exposure time and after $2 \mathrm{~h}$ immersion in distilled water.
\end{abstract}

Keywords: Decay resistance; Hardness; Water absorption; Thickness swelling; Bagasse plastic composite; Coniophora puteana; Trametes vesicular

Contact information; a: Department of Wood Science and Paper Technology, Karaj Branch, Islamic Azad University, Karaj, Iran; b: Department of Wood Science and Paper Technology, Chalous Branch, Islamic Azad University, P.O. Box: 46615/397, Mazandaran, Iran.

*Corresponding author: hashemi@kiau.ac.ir /skh_hosseini@yahoo.com

\section{INTRODUCTION}

Plant fibres from agricultural crops are renewable materials that have potential for creating green products and replacing synthetic materials in such applications as composite panels (Khalil et al. 2001). Bagasse is a source of natural fibers that remains after sugar cane stalks are crushed to extract their juice. Bagasse is also one of the most important non-wood lignocellulosic raw materials available for papermaking mills in Iran. Annually approximately 4.3 million tones of bagasse are produced in Iran, and the production is mainly centered in the southwestern province of Khuzestan (Najafi et al. 2009). To obtain bagasse, a series of mechanical and chemical procedures is used. Because the bagasse fiber is coarse and stiff relative to other available cellulosic fibers, it 
is suitable for making nonwoven products. Nonwoven materials are becoming important industrial materials with diverse end-use applications such as insulation, sound deadening materials, sorbents, and geotextiles (Collier 1995). Nonwoven bagasse materials are also biodegradable, and therefore they are more attractive to industries either as replacement for synthetic materials or in use as reinforcement materials for a polymer matrix.

During the last few decades, considerable effort has been devoted to increasing the utilization of bagasse. However, large quantities of this raw material are still left unused or burnt. A relatively simple possibility is to use bagasse as reinforcing filler for thermoplastics, whereby it can replace wood in applications such as furniture and interior panels (Monteiro et al. 1998).

It was first thought that mixing plastic and natural fiber together would result in plastic encapsulation of natural fiber, which would prevent moisture absorption and fungal decay (Ibach et al. 2008). Zabihzadeh et al. (2009) investigated the influence of fungal decay on the weight loss, long-term water absorption, flexural modulus, flexural strength, and unnotched impact strength properties of a commercial extruded bagasse/PP composite. They reported that the water absorption capacity of brown-rotted samples was significantly higher than that of white-rotted ones. They also found that brown-rot fungus caused more weight loss than the white-rot fungus. Modulus of rupture and modulus of elasticity were shown to decline after incubation with fungi. The brown-rot fungus generally caused a greater reduction in flexural strength than did the white-rot fungus. Fungal decay had no significant influence on unnotched impact strength.

New applications and end uses of wood-plastic composites (WPCs) have been found in decking flooring, outdoor facilities, window frames, various construction materials, and bathroom parts for example (Carig et al. 2003), and water absorption is one of the most important characteristic WPCs exposed to environmental conditions that determine their end use applications. Therefore, as a limiting parameter, water absorption has to be taken into account in the design of WPCs for final applications (Khan et al. 2003; Adhikary et al. 2008).

The availability of moisture is a necessity for decay to occur in a material. Although moisture uptake in natural fiber thermoplastic composites occurs relatively slowly, moisture levels in the outer $5 \mathrm{~mm}$ of commercial products have been shown to be sufficient for fungal attack (Schrip et al. 2008). A problem associated with using natural fibres in composites is their high moisture absorption and dimensional instability (swelling). Swelling of fibers can lead to micro-cracking of the composite and degradation of mechanical properties (Stamboulis et al. 2000). Although there has been considerable research devoted on the weight loss, water absorption, and thickness swelling of bagasse plastic composites (BPC) (Zabihzadeh et al. 2009), there are few reports about the effect of fungal exposure times on the weight loss, hardness, moisture absorption, and thickness swelling of natural fiber plastic composites.

The objective of this study is to evaluate the influence of fungal exposure times $(8,12$, and 16 weeks) on the weight loss of bagasse refiner mechanical pulp fiber (BRMPF) plastic composites against wood-degrading fungi. The hardness, water absorption, and thickness swelling behavior of the composites were analyzed prior to and after incubation with brown- and white-rot fungi also. 


\section{EXPERIMENTAL}

\section{Materials}

The polymer matrix used in this study was polypropylene (PP) with a melt flow index of 7-10 gr/10 min, and a density of $0.90 \mathrm{~g} / \mathrm{cm}^{3}$ (supplied by Bandar Imam Petrochemical Co, Iran). The lignocellulosic material used as the reinforcing filler in the composite was fresh sugarcane bagasse (Saccharum officinarium L.), which was refined by the refiner mechanical pulping (RMP) process. Maleic anhydride polypropylene (MAPP) was obtained from Eastman Chemical Products, Inc., as Epolene G-3003 ${ }^{\mathrm{TM}}$ polymer with $8 \%$ acid anhydride and a molecular weight of 103,500 . It was used as coupling agent.

\section{Composite Preparation}

Before preparation of samples, bagasse fiber was dried in an oven at $65 \pm 2{ }^{\circ} \mathrm{C}$ for 24 hours. The mass ratio of bagasse fiber (BF) to polypropylene (PP) was controlled at 40:60 for all blends. The amount of coupling agent was fixed at $2 \%$ for all formulations. The mixing was carried out with a rectangular mold box with a size of $36 \times 31 \mathrm{~cm}^{2}$ and manually formed. The mats were then compressed on aluminum cauls in a hot press (oil hydraulic press, Burkle L100) at a temperature of $190^{\circ} \mathrm{C}$ using a pressure of $3 \mathrm{MPa}$ for 6 min. This was the amount of time necessary to reach the melting temperature of the PP in the core of the panels. Teflon films were used to avoid the adhesion of MAPP to the stainless surface of the mold. Stops were used to produce panels at a given thickness. All panels were pressed to an average target thickness of $10 \mathrm{~mm}$. The target density was $1.02 \mathrm{~g} / \mathrm{cm}^{3}$. The edge of the panel had lower density than the rest of the panel. Thus the edges were trimmed off, and the final panel size was $32 \times 27 \mathrm{~cm}^{2}$. This allowed for less variability in density (hence properties) within each panel. The specimens were stored under controlled conditions $\left(50 \%\right.$ relative humidity and $\left.23{ }^{\circ} \mathrm{C}\right)$ for at least 40 hours prior to testing.

\section{Decay Test}

Malt extract agar was used at a concentration of $48 \mathrm{~g} / \mathrm{L}$ as the culture medium. Purified white-rot (Trametes versicolor) and brown-rot (Coniophora puteana) fungi were used in this study as the biological degradation agents.

The purified white- and brown-rot fungi were transferred to Petri dishes containing malt extract agar under sterile hood using sterile pincers. The dishes were kept at 25 ${ }^{\circ} \mathrm{C}$ for one week until the culture medium was fully covered by the fungi. The cultured fungi were transferred into kolle-flasks containing the culture medium that were incubated for two weeks at $25^{\circ} \mathrm{C}$. Each test was run in five replicates, and the average values are reported.

The BPC test specimens of $30 \mathrm{~mm} \times 30 \mathrm{~mm} \times 7.91 \mathrm{~mm}$ were mounted over two 3$\mathrm{mm}$ platforms and placed in the kolle-flasks. The flasks containing the fungi and the $\mathrm{BPC}$ specimens were stored in an incubator for 8,12 , and 16 weeks at $25^{\circ} \mathrm{C}$ and $75 \%$ relative humidity.

Dry weights of the specimens were measured after $24 \mathrm{~h}$ at $103 \pm 2{ }^{\circ} \mathrm{C}$ and weight losses were calculated using the following equation, 


$$
\text { Weight loss }(\%)=\frac{(M b-M a)}{M b} \times 100
$$

where $M b$ and $M a$ denote the oven-dry weights prior to and after incubation with fungi, respectively.

\section{Hardness Test}

Hardness tests were carried out according to ASTM D 1037 specifications with an Instron hardness tester model 4486 and 10KN load-cell, and of each group, five specimens were tested. The cross-head speed was $5 \mathrm{~mm} / \mathrm{min}$ (The amount of ball penetration in the specimen is $5.6 \mathrm{~mm}$ according to wood hardness standard, but because of the rupture of specimens at this rate, it was modified to $2 \mathrm{~mm}$ ).

\section{Water Absorption and Thickness Swelling Test}

The water absorption and thickness swelling tests were carried out according to ASTM D 570-98 (1998) for 2 and $24 \mathrm{~h}$ immersion in distilled water at room temperature. Four specimens of BPC were dried in an oven for $24 \mathrm{~h}$ at $103 \pm 2{ }^{\circ} \mathrm{C}$. The specimens were then placed in distilled water. At the end of immersion period, the specimens were removed from the distilled water and the surface water was wiped off using blotting paper and wet mass values were determined. Water absorption (WA \%) and thickness swelling (TS \%) was calculated using the following equations,

$$
\begin{aligned}
& W A(\%)=\frac{W A t-W A o}{W A o} \times 100 \\
& T S(\%)=\frac{T S t-T S o}{T S o} \times 100
\end{aligned}
$$

where WAo, TSo, TSt, and WAt denote the oven-dry weight and thickness swelling; and weight and thickness swelling after $t$ time, respectively.

\section{Statistical Analysis}

Statistical analysis was conducted using the SPSS program in conjunction with analysis of variance (ANOVA). Duncan's multiple range test (DMRT) was used to test statistical significance at $\alpha=0.05$ level.

\section{RESULTS AND DISCUSSION}

The results of ANOVA, the mean values, and standard deviation from weight loss, hardness, water absorption, and thickness swelling in the BPC are summarized in Table 1, which indicates significant differences based on Duncan's test. Each value in Table 1 is the average of five replications for tests of weight loss and hardness, or four replications in the case of tests of water absorption and thickness swelling. 
Table 1. The Average and Standard Deviation for Weight Loss, Hardness, Water Absorption, and Thickness Swelling Measurements of the BPC Samples

\begin{tabular}{|c|c|c|c|c|}
\hline \multirow[b]{2}{*}{ Test Type } & \multirow[b]{2}{*}{ BPC } & \multicolumn{3}{|c|}{ Fungal Exposure Times (Weeks) } \\
\hline & & 8 & 12 & 16 \\
\hline \multirow{2}{*}{$\begin{array}{c}\text { Weight Loss } \\
(\%)\end{array}$} & Brown-Rotted & $3.29 \pm 0.85^{a}$ & $5.67 \pm 0.30^{b c}$ & $6.32 \pm 0.83^{\mathrm{cd}}$ \\
\hline & White-Rotted & $3.15 \pm 0.39^{a}$ & $5.12 \pm 0.46^{b}$ & $7.15 \pm 1.10^{d}$ \\
\hline \multirow{3}{*}{$\begin{array}{l}\text { Hardness } \\
\text { (Shore D) }\end{array}$} & Control & $77.60 \pm 0.85^{d}$ & $77.60 \pm 0.85^{\mathrm{d}}$ & $77.60 \pm 0.85^{d}$ \\
\hline & Brown-Rotted & $70.40 \pm 0.38^{c}$ & $66.63 \pm 0.83^{a b}$ & $66.20 \pm 1.51^{a b}$ \\
\hline & White-Rotted & $70.45 \pm 1.19^{c}$ & $67.35 \pm 1.85^{b}$ & $65.45 \pm 0.82^{a}$ \\
\hline \multirow{6}{*}{$\begin{array}{c}\text { Water } \\
\text { Absorption } \\
(\%)\end{array}$} & Control 2 h Water Soaked & $3.82 \pm 0.29^{a}$ & $3.82 \pm 0.29^{a}$ & $3.82 \pm 0.29^{a}$ \\
\hline & Brown-Rotted 2 h Water Soaked & $6.63 \pm 0.54^{c}$ & $5.90 \pm 0.52^{\mathrm{bc}}$ & $4.92 \pm 0.21^{b}$ \\
\hline & White-Rotted $2 \mathrm{~h}$ Water Soaked & $6.70 \pm 0.52^{c}$ & $6.51 \pm 0.89^{c}$ & $5.71 \pm 0.35^{\mathrm{bc}}$ \\
\hline & Control $24 \mathrm{~h}$ Water Soaked & $7.77 \pm 0.74^{d}$ & $7.77 \pm 0.74^{d}$ & $7.77 \pm 0.74^{d}$ \\
\hline & Brown-Rotted $24 \mathrm{~h}$ Water Soaked & $10.49 \pm 0.68^{\dagger}$ & $9.90 \pm 0.70^{\text {ef }}$ & $9.03 \pm 0.58^{\mathrm{e}}$ \\
\hline & White-Rotted $24 \mathrm{~h}$ Water Soaked & $10.27 \pm 0.89^{\dagger}$ & $10.30 \pm 1.24^{\dagger}$ & $10.04 \pm 0.60^{\mathrm{et}}$ \\
\hline \multirow{6}{*}{$\begin{array}{l}\text { Thickness } \\
\text { Swelling } \\
(\%)\end{array}$} & Control 2 h Water Soaked & $2.45 \pm 0.14^{\text {abcd }}$ & $2.45 \pm 0.14^{\mathrm{abcd}}$ & $2.45 \pm 0.14^{\mathrm{abcd}}$ \\
\hline & Brown-Rotted 2 h Water Soaked & $1.82 \pm 1.31^{\text {ab }}$ & $1.40 \pm 1.01^{\mathrm{a}}$ & $2.60 \pm 1.01^{\mathrm{a}}$ \\
\hline & White-Rotted 2 h Water Soaked & $2.37 \pm 0.71^{\text {abcd }}$ & $2.36 \pm 0.65^{\mathrm{abcc}}$ & $1.89 \pm 1.11^{\mathrm{abc}}$ \\
\hline & Control $24 \mathrm{~h}$ Water Soaked & $6.28 \pm 0.77^{\mathrm{e}}$ & $6.28 \pm 0.77^{\mathrm{e}}$ & $6.28 \pm 0.77^{\mathrm{e}}$ \\
\hline & Brown-Rotted 24 h Water Soaked & $2.98 \pm 0.86^{\mathrm{abcd}}$ & $3.55 \pm 1.53^{\mathrm{bcd}}$ & $3.61 \pm 1.14^{\mathrm{cd}}$ \\
\hline & White-Rotted $24 \mathrm{~h}$ Water Soaked & $3.77 \pm 0.66^{\mathrm{d}}$ & $3.46 \pm 1.55^{b}$ & $4.10 \pm 1.44^{\mathrm{d}}$ \\
\hline
\end{tabular}

Values are mean and standard deviation. Results with different letters are significantly different (Duncan's test)

The results of Duncan's test (Table 1), indicated that the type of fungus and fungal exposure times had significant effect on weight loss of the BPC samples $(\mathrm{P}<0.05)$ for 8,12 , and 16 weeks. The results indicated that both fungal types were equally sensitive to determine fungal decay in WPC. The patterns of variations in weight loss of the BPC samples with brown- and white-rot fungi for 8, 12, and 16 weeks, as a function of fungus type and fungal exposure times, are shown in Table 1.

The biodegradability of polypropylene is very limited (Khavkine et al. 2001; Zabihzadeh et al. 2009). Therefore, calculation of weight loss was based on bagasse filler, because this represents the predominant fungal food source in the composite. Also, it has previously been demonstrated that lower levels of wood filler in WPC decrease the growth substrate available for microorganisms (Mankowski and Morrell 2000; Verhey et al. 2001b; Pendleton et al. 2002; Simonsen et al. 2004). However, it can be also concluded that only bagasse fiber in surface regions would be accessible to fungal attack (Goodell et al. 1997).

Little consistent information on fungal resistance is available in the literature (Clemons and Ibach 2003). White- and brown-rot fungi caused a weight loss of about 9 and $10.5 \%$, respectively in a commercial extruded BPC was made with $30 \%$ polypropylene, $68 \%$ bagasse flour and $2 \%$ MAPP by weight for 14 weeks (Zabihzadeh et al. 2009). Morris and Cooper (1998) reported fungal growth on WPCs decking after 4 years of service in Florida. Mankowski and Morrell (2000) evaluated several proprietary WPCs by laboratory soil block tests. Weight loss varied from $0.4 \%$ to $20.4 \%$ depending on the fungi used and type of composite. Researchers have also investigated the fungal resistance of model composites, but the literature to date is far from conclusive (Clemons and Ibach 2003). Khavkine et al. (2003) found that fungal attack caused little weight loss 
in polyethylene composites containing $40 \%$ to $70 \%$ wood, despite good fungal colonization on the composite surfaces and a conditioning procedure that included oven drying at $105{ }^{\circ} \mathrm{C}$ for $24 \mathrm{~h}$, a $2 \mathrm{~h}$ boil, and a $24 \mathrm{~h}$ water soak. However, using a modified soil block procedure, Verhey et al. (2001) found significant weight loss in composites containing $60 \%$ or greater wood content.

White- and brown-rot fungi caused a higher weight loss of 6.3 and $7.2 \%$ for 16 weeks, respectively in this study. The greater weight loss of BPC samples exposed to white-rot fungus in an incubator could indicate a difference in decay mechanism (Zabihzadeh et al. 2009). Even small mass losses in the early stages of decay are associated with significant strength losses, especially when the wood is colonized by brown rot fungi (Wilcox 1987).

The results of Duncan's test (Table 1), indicated that fungus type and fungal exposure times had significant effect on hardness of the BPC samples $(\mathrm{P}<0.05)$ for 12 , and 16 weeks.

Brown-rot fungi can degrade crystalline cellulose in wood (Cowling 1961; Kirk 1973) and cause rapid de-polymerization of cellulose in wood before losses in total wood substance are detected. Although these fungi can also degrade lignin, they preferentially metabolize the cellulose (the $\mathrm{S}_{2}$ layer of wood cell wall in the early stages of degradation of wood is degraded extensively) and hemicellulose, leaving an amorphous, brown, crumbly residue that is rich in lignin (Highley 1987; Enoki et al. 1988). It can be postulated that because cellulose and hemicellulose are play an important role in increase of wood strength, this can explain why the hardness of brownrotted BPC samples was lower than white-rotted BPC samples.

The results of Duncan's test (Table 1), indicated that fungal type and fungal exposure times had significant effect on water absorption of the BPC samples $(\mathrm{P}<0.05)$ for 12 , and 16 weeks. The patterns of variations in water absorption of the BPC samples with brown- and white-rot fungi for 8,12 , and 16 weeks, as a function of fungus type and fungal exposure times, are shown in Table 1. In the all cases, the water absorption of brown- and white-rotted BPC samples decreased with increasing of fungal exposure and after immersion in distilled water. The BPC samples absorbed water rapidly during the first stages, where the possible reason can be that the hydrophilic character of bagasse is responsible for the water absorption in the samples (Zabihzadeh et al. 2009).

Because of its common use to assess susceptibility of exterior wood building products to decay, ASTM D 1413 was examined for assessing WPCs intended to replace these same wood products. However, WPCs absorb moisture very slowly, and both the 3 weeks conditioning time and 12 weeks incubation time are insufficient for the samples to reach equilibrium for the sample size (19 $\mathrm{mm}$ cubes) used in the standard (Clemons and Ibach 2003).

Water adsorption of BPC samples was actually a lot higher after either type of rotting and was significantly higher than that of control BPC specimens (Zabihzadeh et al. 2009). Various possible reasons for the greater water absorption and moisture penetration into the BPC samples exposed to brown- and white- rot fungi in an incubator could be proposed, where the main mechanism is the diffusion of water molecules inside the microgaps between polymer chains (Zabihzadeh et al. 2009). It might alternatively be proposed that rotting created channels for the water to enter into the BPC structure. Two 
mechanisms by which this could occur are capillary transport into the gaps and flaws at the interfaces between fibers and polymer, and transport by microcracks in the matrix, which formed during the compounding process. Other possible mechanisms may involve diffusion behavior (Fickian diffusion processes) in the polymer matrix of the composites (Zabihzadeh et al. 2009).

In the all cases, the thickness swelling of brown- and white-rotted BPC samples increased with increasing of fungal exposure and water soaking times with the exception of white-rotted BPC samples after $2 \mathrm{~h}$ immersion in distilled water. According to Table 1 , there was less thickness swelling in both the rotted samples. The possible reason for less thickness swelling of white- and brown-rotted BPC samples could be the broken down nature of the bagasse fibers, such that they no longer were effective in swelling the structure.

White-rot fungi deplete all components of the wood cell wall during decay, but some species cause selective removal of the lignin in wood. In both the decay types, the lignin in the wood cell wall being decayed is completely depleted, but some white-rot fungi can degrade the lignin in the wood preferentially to cellulose (Goodell et al. 1953IV). It can be said that the removal of lignin as a hydrophobic component and the preservation of much of the holloceloluse as a hydrophilic component tend to favor increased water absorption of white-rotted BPC samples. Thus, the water absorption of white-rotted BPC samples was higher than brown-rotted and control BPC samples for all weeks of fungal exposure times and after $2 \mathrm{~h}$ and $24 \mathrm{~h}$ immersion in distilled water with the exception of 8 weeks after $24 \mathrm{~h}$ immersion in distilled water. Because an increase of water absorption causes an increase of thickness swelling, therefore the thickness swelling of white-rotted BPC samples was higher than brown-rotted BPC samples for all weeks of fungal exposure times and after $2 \mathrm{~h}$ and $24 \mathrm{~h}$ immersion in distilled water.

\section{Electron Microscopy}

SEM micrographs showing the fracture surfaces of the composites at different times of fungal exposure times are given in Fig. 1. As can be seen, the extent of degradation increased with increasing exposure time to fungus. These results were consistent with the observed losses of mass. Structural decomposition of BPC samples was considerable after 16 weeks of exposure.

\section{CONCLUSIONS}

1. The largest weight loss was for composites exposed to Trametes versicolor.

2. The hardness values for brown- and white-rotted bagasse fiber-plastic (BPC) composite samples were lower than for control samples, and the hardness of white-rotted BPC samples were lower than for brown-rotted BPC samples as a result of fungal attack on the cellulose and hemicellulose components.

3. The highest water absorption was observed in the brown-rotted composite samples for 8 weeks fungal exposure time and after 24 hours, and the lowest was noted in the control composite samples after 2 hours.

(continued after Fig. 1) 
a
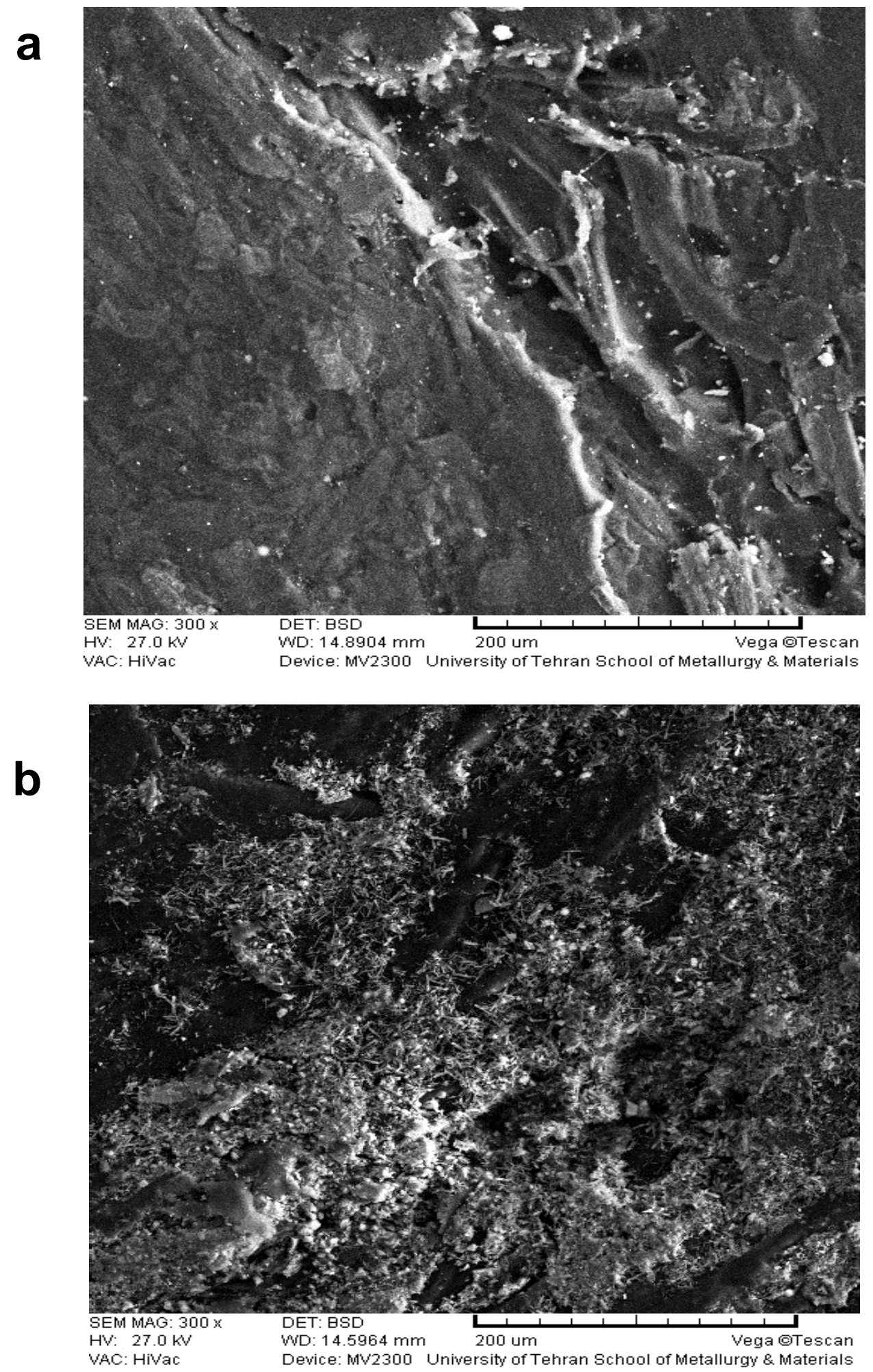

Figure 1(a \& b). SEM micrograph of the fracture surfaces in the composites at different times of fungal exposure times (a) control sample (b) 8 weeks (c) 12 weeks (d) 16 weeks 

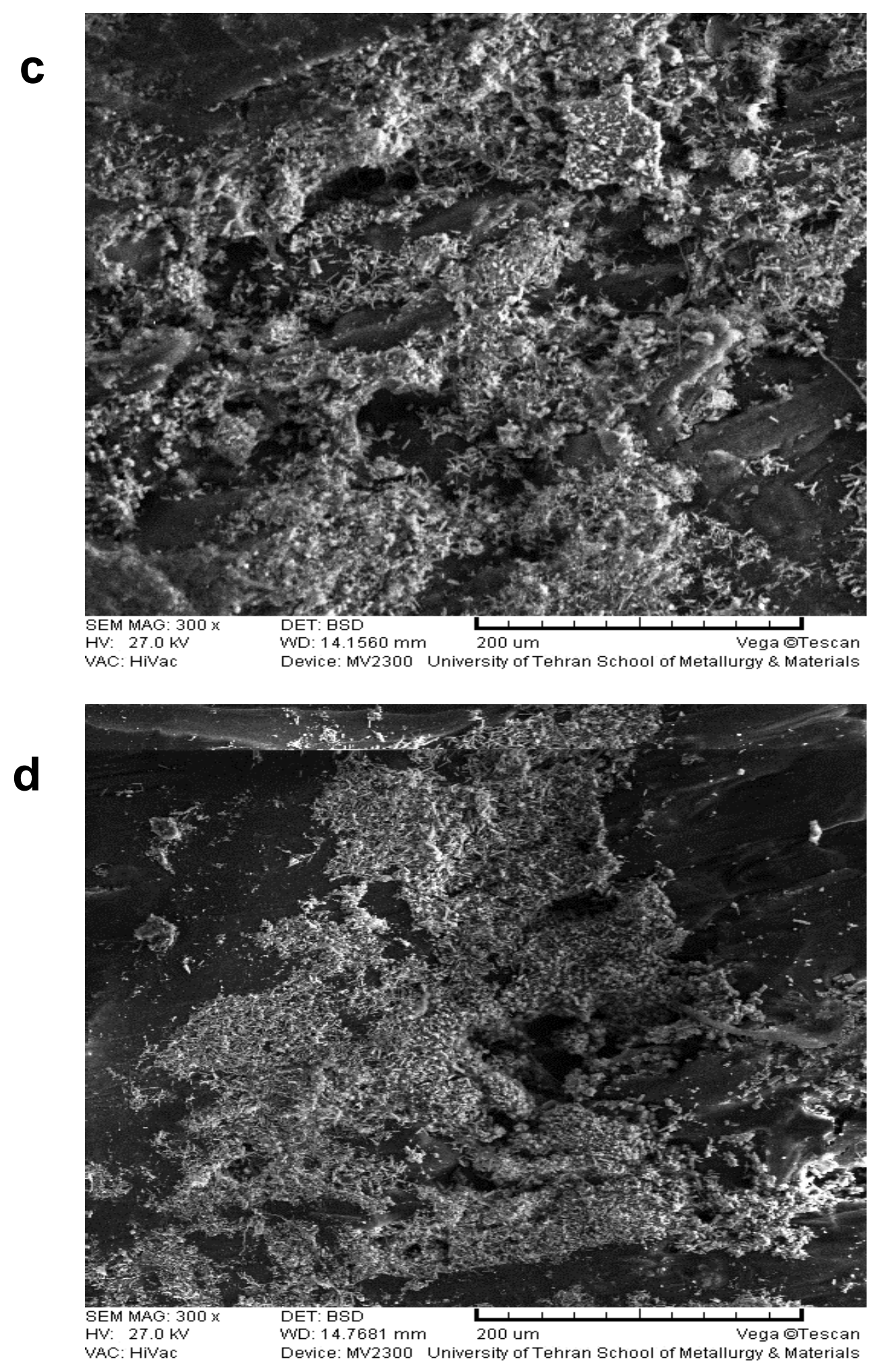

Figure 1(c \& d). SEM micrograph of the fracture surfaces in the composites at different times of fungal exposure times (a) control sample (b) 8 weeks (c) 12 weeks (d) 16 weeks 
4. The highest thickness swelling was observed in the control composite samples after 24 hours immersion in distilled water, and the lowest thickness swelling was found in the white-rotted composite samples for 16 weeks fungal exposure time and after 2 hours.

5. The SEM micrographs showed that the extent of degradation increased with increasing exposure time to fungus.

\section{REFERENCES CITED}

Adhikary, K. B., Pang, S., and Staiger, M. P. (2008). "Long-term moisture adsorption and thickness swelling behavior of recycled thermoplastics reinforced with Pinus radiata sawdust," Chemi. Engineer. J. 142, 190-198.

ASTM D 570-98 (1998). Standard Test Method for Water Absorption of Plastics, Philadelphia, PA., USA.

ASTM D 1413-99 (2002). Standard Test Method for Wood Preservatives by Laboratory Soil-Block Cultures, Annual Book of Standards, Vol. 4(10), West Conshohockon, PA.

British Standard 838. (1961). "Methods of test for toxicity of wood preservatives to fungi," Philadelphia, PA., USA.

Clemons, C. M., and Ibach, R. E. (2003). "Application of laboratory fungal resistance tests to solid wood and wood-plastic composite," Plastics in Building Construction 27(2), 7-14.

Collier, J. R., Collier, B. J., Thames, J. L., and Elsunni, M. M. (1995). "Production and evaluation of sugar cane geotextiles," Report submitted to Louisiana Transportation Research Center, Baton Rouge, Louisiana.

Cowling, E. B. (1961). "Physical and chemical characteristics of glycopeptide from wood decay fungi," US Dep. Agric. Tech. Bull. No. 1258, 1-75.

Enoki, A., Tanaka, H., and Fuse, G. (1988). "Physical and chemical characteristics of glycopeptide from wood decay fungi," Holzforchung 42, 85-93.

Goodell, B., Daniel, G., Liu, J., Mott, L., and Frank, R. (1997). "Wood composite protection," Forest Prod. J. 47(11/12), 75-80.

Goodell, B., Nicholas, D. D., and Schultz, T. P. (1953-IV). "Physical and chemical characteristics of glycopeptide from wood decay fungi," American Chemical Society. Meeting (221 ${ }^{\text {st }}: 2001$ : San Diego, Calif.) V. Series.

Highly, T. L. (1987). "Physical and chemical characteristics of glycopeptide from wood decay fungi," Mater. Org. 22, 39-45.

Ibach, R. E., Clemons, C. M., and Schumann, R. L. (2007). "Wood-plastic composites with reduced moisture: Effects of chemical modification on durability in the laboratory and field," In: 9th International Conference on Wood and Biofibre Plastic Composites, Madison, Wisconsin, USA.

Khalil, H. P. S. A., Ismail, H., Rozman, H. D., and Ahmad M. N. (2001). "The effect of acetylation on interfacial shear strength between plant fibres and various matrices," Europ Polym. 37(5), 1037-1045. 
Khan, M. A., Islam, M. N., Alam, M. K., and Zaman, M. A. (2003). "Study of water absorption behavior in wood plastic composites by using neutron radiography tecniques," J. Plast. Tech. and Engineer. 42, 925-934.

Khavkine, M., Kazayawoko, M., Law, S., and Balatinecz, J. J. (2001) "Durability of wood flour-thermoplastic composites under extreme environmental conditions and fungal exposure," International Journal of Polymeric Materials 26, 255-269.

Kirk, T. K., and Highley, T. L. (1973). "Physical and chemical characteristics of glycopeptide from wood decay fungi," Phytopathology, 63, 1342-1355.

Monteiro, S. N., Rodriquez, R. J. S., and De Souza, M. V. (1998). "Sugar cane bagasse waste reinforcement in low cost composites," Advanced Performance Material 5(3), 183-191.

Morris, P. I., and Cooper, P. (1998). "Recycled plastic-wood composite lumber attacked by fungi," Forest Products Journal 48(1), 86-88.

Mankowski, M., and Morrell, J. J. (2000). "Patterns of fungal attack in wood-plastic composites following exposure in a soil block test," Wood Fiber Sc. 32(3), 341345.

Najafi, G., Ghobadian, B., Tavakoli, T., and Yusaf, T. (2009). "Potential of bioethanol production from agriculture wastes in Iran," Renewable and Sustainable Energy. 13(6/7), 1418-1427.

Pendleton, D. E., Hoffard, T. A., Adcock, T., Woodward, B., and Wolcott, M. P. (2002). "Durability of an extruded HDPE/wood composite," Forest Prod. J. 52(6), 21-27.

Schirp, A., Ibach, R. E., Pendleton, D. E., and Wolcott, M. P. (2008). "Development of commercial wood preservatives: Efficacy, Environmental, and Health Issues, Biological degradation of wood-plastic composites (WPC) and strategies for improving the resistance of WPC against biological decay," ACS Symposium Series, 982.

Simonsen, J., Freitag, C. M., Silva, A., and Morrell, J. J. (2004). "Wood/plastic ratio: Effect on performance of borate biocides against a brown rot fungus," Holzforschung 58, 205-208.

Stamboulis, A., Baillie, C. A., Garkhil, S. K., Van Melick, H. G. H., and Peijs C. (2000). "Environmental durability of flax fibres and their composites based on polypropylene matrix," Applied Composite Materials 7(5-6), 273-294.

Verhey, S., Laks, P., and Richter, D. (2001) "Laboratory decay resistance of wood fibre/thermoplastic composites," Forest Products Journal, 51(9), 44-49.

Wilcox, W. W. (1987). "Concepts in the development of new accelerated test methods for wood decay," Wood Fiber, 9, 252-257.

Zabihzadeh, S. M., Hosseini Hashemi, S. K., Mehregan Nikoo, H., and Sepidehdam, S. M. J. (2009). "Influence of fungal decay on physico-mechanical properties of a commercial extruded bagasse/PP composite," Journal of Reinforced Plastics and Composite. doi, 10.1177/0731684409340596.

Article submitted: April 30, 2011; Peer review completed: June 18, 2011; Revised version received and accepted: July 5, 2011; Published: July 9, 2011 